Forensic Psychology

\title{
Perceptions around adult and child sex offenders and their rehabilitation as a function of education in forensic psychology independent of traditionalism and perpetrator sex
}

\author{
Megan Rothwell ${ }^{\mathrm{a}}$, Dean Fido ${ }^{\mathrm{b}}$, Nadja Heym ${ }^{\mathrm{a},}$ \\ ${ }^{a}$ Nottingham Trent University, UK \\ ${ }^{\mathrm{b}}$ University of Derby, UK
}

\section{A R T I C L E I N F O}

\section{Keywords:}

Public perceptions sex offenders

Rehabilitation

Female sex offenders

Victim age

Traditionalism

\begin{abstract}
A B S T R A C T
Literature pertaining to individuals with sexual convictions typically reports punitive views about their crimes, sentences, and overall effectiveness of rehabilitation, with such perceptions partially driven by offence demographics such as victim age and perpetrator sex. This manuscript extends this literature through the exploration of perceiver characteristics of self-reported traditionalism and education in forensic psychology as mechanisms of perceptions and awareness. Participants $(\mathrm{N}=101 ; 60 \%$ forensic psychology students; $40 \%$ general public) read online vignettes related to sexual offences (manipulating perpetrator sex and victim age), and completed measures of perceptions of sex offenders, perceived rehabilitation efficacy and traditionalism. Members of the general population (without a background of education in forensic psychology) reported harsher views towards individuals with sexual convictions and their rehabilitation, relative to students of forensic psychology, independent of their greater traditionalism. There was no main effect of or interaction with perpetrator sex. Whilst participants endorsed more negative perceptions towards sex offenders of child than adult victims, this did not extent to differences in perceptions regarding their rehabilitation. Findings reported here indicate a need for greater understanding as to the factors that might moderate perceptions towards individuals with sexual convictions and have implications for the promotion of sex offender rehabilitation programmes. Understanding the root of such public attitudes is a key step for creating and improving associated policies.
\end{abstract}

\section{Introduction}

The term sex offender evokes extremely negative emotions and perceptions including disgust, fear and moral outrage (Gidycz, Orchowski, King, \& Rich, 2008; Olver \& Barlow, 2010; Willis, Levenson, \& Ward, 2010), and individuals with sexual convictions are typically perceived more negatively, dangerous, violent, unpredictable and unchangeable than perpetrators of other (non-sexual) crimes (e.g., Rogers \& Ferguson, 2011; Weekes, Pelletier, \& Beaudette, 1995). They are stereotypically labelled as predators, thought to be more likely to reoffend and resistant to treatment interventions (Cromer \& Goldsmith, 2010; Galeste, Fradella, \& Vogel, 2012). However, such perceptions are contradicted by evidence; with recent recidivism data indicating that over a nine year period, fewer $(<67 \%)$ individuals with sexual convictions were rearrested (for any offences) than those with convictions for property, drug or violent crimes, as well as public order offences (Alper \& Durose, 2019).
Cohen's (1972) Moral Panic Theory highlights the influential role of the media in exploiting moral panic and facilitating sensationalization, stigma and stereotyping of offenders. As such attitudes are reinforced by sensationalist media coverage of rare - but prolific - cases (Brown, Deakin, \& Spencer, 2008; Radley, 2001) that ultimately impact the way that such individuals are treated. Thus, by exploiting society's fear of sexual victimization, such media depictions might contribute to harsher public views of individuals with sexual convictions. So much so that the general population exhibits comparatively harsher views towards them than perpetrators of other crimes, including murder (Craig, 2005; King \& Roberts, 2017; Redlich, 2001).

Such perceptions also lead to more punitive views regarding sex offenders' rehabilitation. Whilst the public generally agrees that sex offenders should receive treatment (Valiant, Furac, \& Antonowicz, 1994), rehabilitation success is often considered to be poor (Laczko-Kerr \& Berliner, 2003) with the public indicating a preference for harsher

\footnotetext{
* Corresponding author. Nottingham Trent University, Taylor Building, 50 Shakespeare Street, Nottingham, NG1 4FQ, UK.

E-mail address: nadja.heym@ntu.ac.uk (N. Heym).
} 
punishments instead of rehabilitation (Rogers \& Ferguson, 2011), and even the use of capital punishment (Mancini \& Mears, 2010; Rosselli \& Jeglic, 2017). This reflects a desire for Just Deserts sentencing, whereby levels of punishment reflect the perceived severity of the crime committed (Carlsmith, Darley, \& Robinson, 2002). However, a recent meta-analysis spanning the UK, USA, and Canada indicates that rehabilitation for sexual offending can be successful, with cognitive behavioural therapy specifically, leading to a reduction in sexual recidivism by 31\% (Lösel \& Schmucker, 2005).

Thus, a lack of awareness of rehabilitation success alongside more traditional views and negative preconceptions in the general public may underpin more punitive responses regarding sex offenders and their rehabilitation. The current paper concurrently examines some of the factors that might systematically impact on the perception of sexual offenders and associated rehabilitative pathways - from an offence and perceiver perspective. Specifically, we re-examine the roles of victim age and perpetrator sex as offence characteristics and develop this literature further through the incorporation of perceiver traditionalism and prior education around sexual offences and rehabilitation.

\subsection{Offence characteristics: victim age and perpetrator sex}

Perceptions of individuals with sexual convictions are impacted by the demographics of the victim. In particular, perpetrators in cases involving child victims are considered more immoral, mentally ill or deviant, and overall, more negatively than those involving adult victims (Rogers, Hirst, \& Davies, 2011; Weekes et al., 1995). Moreover, perceived dangerousness of, and fear towards, individuals with sexual convictions is higher in cases involving child victims (Kernsmith, Craun, \& Foster, 2009; Redlich, 2001; Weekes et al., 1995). These offences have been consistently shown to be considered as most deserving of harsher punishments by public perceptions (Hilinski-Rosick, Freiburger, \& Verheek, 2014; Mancini \& Mears, 2010; Pickett, Mancini, \& Mears, 2013). For example, Mears, Mancini, Gertz, and Bratton (2008) reported that $76 \%$ of their sample supported residency restrictions for perpetrators with child victims, and $65 \%$ the use of capital punishment, relative to $47 \%$ supporting latter for adult victims (Mancini \& Mears, 2010). The Just Deserts model (Carlsmith et al., 2002; Kirchengast, 2010) suggests the punishment that is imposed on offenders reflects the moral reprehensibleness of the offence. As such, increased perceptions of severity and immorality of sexual offences against children is likely to contribute to more punitive views towards the offender.

In terms of perpetrator characteristic, when asked to describe a sex offender (in lay terms), individuals typically think of a male offender whose victim is female (Gakhal \& Brown, 2011; Griffin \& Wooldredge, 2006). Although males are primarily the perpetrators of sexual offences, females comprise around 5\% of perpetrators internationally (Cortoni, Hanson, \& Coache, 2010). However, confidential child helplines within the UK suggest that the dark numbers may be higher with $17 \%$ of 12,268 calls involving female perpetrators (NSPCC, 2009 as cited in Elliott \& Ashfield, 2011). Such disparity may partially be attributed to female-driven sexual abuse being obscured through child caring practices such as bathing (Bumby \& Hansen, 1997), and/or underreporting with victims not disclosing their abuse due to feeling ashamed of being assaulted by a female, or even not recognising the behaviour as abusive at all (Steffensmeier, Zhong, Ackerman, Schwartz, \& Agha, 2006; Weiss, 2010).

Consideration of perpetrator sex impacting perceptions is important, because males with sexual convictions receive harsher sentences (Gakhal \& Brown, 2011; McKimmie \& Masser, 2010), are deemed more culpable (Rogers \& Davies, 2007a, 2007b), and are perceived more punitively than their female counterparts (Godfrey, Farrall, \& Karstedt, 2005). Moreover, when perpetrators are the teachers of their victims, relationships involving female perpetrators are considered more acceptable than those involving male perpetrators (Wakefield, 2006). This can be linked to the Chivalry Hypothesis (Anderson, 1976; Fernando Rodriguez, Curry,
\& Lee, 2006), which posits that females are treated more leniently than men due to traditional gender roles asserting that females are held to different standards than men and are not considered fully responsible for their actions. As a result, the criminal justice system treats them in a more lenient manner.

On the other hand, in line with the double-deviance theory (Heidensohn, 1989), there is evidence that females who commit counter-stereotypical offences (such as sexual offences) may be viewed more harshly than males committing the same offence (Viki, Massey, \& Masser, 2005). In particular, traditional stereotypes about females, including being motherly, caring and supportive, would be conflicted by females with sexual offences against children (Bumby \& Hansen, 1997). The inconsistencies with which males and females might be judged and receive more (or less) punitive views for different offences, highlights the need to study these two predictions further in the context of sexual offences. This study attempts to bridge this gap by creating a direct comparison of males and females having committed sexual offences in identical scenarios, alongside the consideration of traditional views.

\subsection{Perceiver characteristics: the role of traditionalism and prior education in forensic psychology}

Traditionalism is defined as attitudes that favour the value and motivational goal of maintaining traditional lifestyles and norms while resisting modern, liberal, and open lifestyles and morality (Bjerkli, 1996). There is often a resistance to change preconceptions, and preference to maintain traditional standards over anything else (Jost, Glaser, Kruglanski \& Sulloway, 2003), which in turn influences stronger attitudes and perceptions (e.g., in political contexts; Bizumic \& Duckitt, 2018). Indeed, in forensic contexts, traditionalism has been associated with harsher views on the sentencing of perpetrators of violent crimes (Huang, Finn, Ruback, \& Friedman, 1996), and scepticism around the efficacy of offender rehabilitation in general (Dozier, 2009). Whilst traditionalism has been considered within more general perceptions of crime, it has not been directly studied in relation to perceptions of sexual offences; however, is likely to also affect perceptions around perpetrators of sexual crimes and may explain some of the perpetrator sex findings discussed previously (e.g., Chivalry Hypothesis).

Finally, whilst much of the literature has focused on members of the general public, it has rarely considered whether awareness and knowledge about sex offender motivations and rehabilitation influences such perceptions and judgments. Evidence suggests that the public holds often inaccurate beliefs about sex offenders, risk of recidivism and effectiveness of rehabilitation (Levenson, Brannon, Fortney, \& Baker, 2007). The lack of awareness and understanding, alongside the influential role of the media in facilitating stigma and stereotyping of offenders (c.f., Moral Panic Theory; Cohen, 1972), may be reflected in more punitive views about sex offences in the general public. Thus, awareness and knowledge is likely an important ameliorating variable, given that training for offender management and provision of educational information pertaining to individuals with sexual convictions leads to reduction in stigmatised views towards such offenders and their rehabilitation (Weekes et al., 1995; Singer \& Cooper, 2009), and greater confidence in the criminal justice system (Kleban \& Jeglic, 2012; Hugo, Bashoff, Traut, Zungu-Dirwai, \& Stein, 2003).

Specifically, psychoeducational interventions have been shown to reduce stereotypes about individuals with sexual offences and led participants to become less negative towards sexual perpetrators (Singer \& Cooper, 2009). In contrast to the general public, students of forensic psychology receive high quality and in-depth information about sexual offences and rehabilitative pathways, which should be reflected in more accurate, and less stereotyped and punitive views. Coincidentally, relative to the general population, students of forensic psychology hold also lower levels of traditional values (Bryant, 2003; Kumar, 2016). Thus, in order to assess to what extent the role of knowledge and education around sex offenders and their rehabilitation may drive more punitive 
perceptions around these issues in the general public, we will directly compare these to students of forensic psychology, whilst also accounting for any differences in more general traditionalism.

\subsection{The current study}

This study aims to [1] consolidate our knowledge on the role of victim age and perpetrator sex on the perceptions of individuals with sexual convictions, and for the first time, both [2] delineate whether such perceptions differ as a function of knowledge (e.g., contrasting education in forensic psychology versus public views), and the [3] potential role of traditionalism in the variation of such perceptions. We hypothesise that perceptions will be more negative in the general public, relative to forensic psychology students, in particular when the perpetrator of the offence is male, relative to female, and when the victim is a child, relative to an adult. The role of traditionalism in driving harsher perceptions towards sex offenders was also considered, by controlling for it in order to assess whether these associations are dependent on traditional values more generally.

\section{Method}

\subsection{Participants}

One hundred and eleven participants initially completed the questionnaire pack; however, 10 data points were removed due to incomplete responses ( $>5 \%$ missing data), leaving a total of 101 participants (aged 18-64 years, $M_{a g e}=26.71 \pm 10.27,65 \%$ female). Of these, 61 were students of forensic psychology (aged 18-33 years, $M_{\text {age }} 20.75 \pm 2.71$, $73 \%$ female) and 40 were members of the public who had never studied forensic psychology (aged 19-64 years, $M_{\text {age }}=35.8 \pm 10.91$, $50 \%$ female). Participants were recruited through social media networks as well as departmental invitations to students studying for a Master's degree in Forensic Psychology, accredited by the British Psychological Society. To standardise for cultural variation, participants were required to be of British nationality and to be based in the UK.

\subsection{Materials}

Demographics. Participants were asked to report their age and sex, and whether they are/were a forensic psychology student or a member of the general public without previous education in forensic psychology.

Perceptions of Sex Offenders scale (PSO; Harper \& Hogue, 2014). The PSO was used to measure attitudes towards sex offenders across 20 items, rated on a 6-point scale from 1 (Strongly Disagree) to 6 (Strongly Agree). Following weighting and reverse scoring of 6 items, total scores ranged between 0 and 100, with higher scores indicative of harsher views of individuals with sexual offences. The scale is split into three sub-factors [1] sentencing and management (e.g., "People who commit sex offences should lose their civil rights (e.g., voting, privacy):" ), [2] stereotype endorsement (e.g., "Most sex offenders do not have close friends"), and [3] risk perception (e.g., "People are far too on edge about the risks posed by sex offenders").

Public Attitudes Towards Sex Offender Rehabilitation (PATSOR; Rogers et al., 2011). The PATSOR was used to measure perceptions of sex offender rehabilitation, and comprises 12 items, rated on a 5-point scale from 1 (Strongly Disagree) to 5 (Strongly Agree). Total scores ranged from 12 to 60 , with higher scores indicative of more negative attitudes towards sex offender rehabilitation. The PATSOR was split into two subscales [1] sex offender rehabilitation (e.g., "Anyone would be foolish to give sex offender a job"): and [2] knowing offenders' area of residence (e.g., "Knowing where sex offenders live will give a false sense of security"). All items were coded so that higher scores reflected a more negative attitude towards sex offenders.

Authoritarianism, Conservatism and Traditionalism scale (ACT; Duckitt, Bizumic, Krauss, \& Heled, 2010). The 12-item Traditionalism subscale of the ACT was used to measure traditionalism in our sample, with each item (e.g., "The "old-fashioned way" and "old-fashioned values" still show the best way to live") rated on a 6-point scale from 1 (Strongly Disagree) to 6 (Strongly Agree). After reverse scoring 4 items (and the removal of 2 items due to religious connotations that could potentially bias results of this study), higher scores were indicative of traditional beliefs.

Vignettes. Four vignettes were created by the research team as a means of establishing a scenario in which perceptions of individuals who have committed sexual offences can be considered, despite sensitivity of the topic. Each vignette was identical, save for the experimental manipulations of the victim's age (adult vs. child) and perpetrator sex (male vs. female). An example vignette is detailed below:

[Ms/Mr] T. Baker is a 37-year-old [female/male] who committed a sexual assault against [a child living in their neighbourhood/one of their neighbours]. [She/He] was subsequently imprisoned for this sexual assault and has been put on the sex offender register. After serving [his/ her] sentence, [she/he] is now being considered for a rehabilitation programme.

\subsection{Procedure}

The study was approved by the institutional ethics review panel of the School of Social Sciences at Nottingham Trent University. Using a Qualtrics online survey, each participant completed demographics and was shown two of the four possible vignettes. They received vignettes with an adult and a child victim (within-subject variable; randomly counterbalanced to reduce order bias) but either with a male or female offender (between-group variable). These were counterbalanced across the two between-group levels of knowledge about sex offenders and their rehabilitation, which was operationalised through the use of the two groups of participants: those from the general public, and those who were either enrolled in or had completed a university degree in forensic psychology. Following each vignette, participants completed the PSO and PATSOR - in response to each specific scenario, and finally the ACT. Participants were debriefed at the end.

\subsection{Statistical analysis}

First, paired sample $t$-tests were conducted to examine differences in perceptions of [a] individuals with sexual offences, and [b] their rehabilitation (using total and subscale scores as DVs) as a function of age of victim (IV: adult vs. child). Second, two $2 \times 2$ MANCOVAs were used to examine the effects of the independent variables perpetrator sex (male vs. female) and knowledge (public vs. forensic psychology students) on perceptions of individuals with sex offences (DV: PSO) and their rehabilitation (DV: PATSOR) for both, young and adult victims, whilst controlling for the covariate of traditionalism. One MANCOVA examined the effects of the IVs on the two total scores of PSO and PATSOR as DVs, the second on the PSO and PATSOR subscale scores as DVs for a more detailed examination of those. Assumptions relating to variable type, linear relationships, homogeneity, and data distribution were met prior to the reporting of inferential statistics.

\section{Results}

\subsection{Comparative analysis}

Descriptive statistics and scale reliabilities are reported in Table 1. All scale reliabilities were at an acceptable level ( 0.70 or above; Nunnelly, 1978). In terms of victim age, only the total PSO scale showed significant differences in responses $(t(100)=-2.11, p<.05)$, such that offenders with sexual convictions against child victims were perceived more negatively than those with adult victims. However, there were no statistically significant differences between scores on the remaining PSO (though marginal for risk perception; $p=.056$ ) and PATSOR subscales 
Table 1

Descriptive Scale Statistics and comparative analyses for victim age.

\begin{tabular}{|c|c|c|c|c|c|c|c|c|}
\hline \multirow[t]{2}{*}{ Subscales } & \multicolumn{3}{|c|}{ Adult Victim } & \multicolumn{3}{|c|}{ Child Victim } & \multirow[t]{2}{*}{$t$} & \multirow[t]{2}{*}{$p$} \\
\hline & Mean & SD & Alpha & Mean & SD & Alpha & & \\
\hline PSO Sentencing and Management & 21.46 & 14.38 & .89 & 22.48 & 14.32 & .88 & -1.77 & .079 \\
\hline PSO Stereotype Endorsement & 10.02 & 5.07 & .9 & 10.31 & 5.26 & .91 & -.34 & .739 \\
\hline PSO Risk Perception & 18.43 & 4.04 & .75 & 19.08 & 3.56 & .74 & -1.93 & .056 \\
\hline PSO Total & 50.09 & 18.55 & .89 & 51.86 & 18.7 & .89 & -2.11 & .038 \\
\hline PATSOR Rehabilitation & 26.25 & 2.07 & .93 & 26.85 & 9.23 & .91 & -1.4 & .166 \\
\hline PATSOR Offender Residence & 8.38 & 2.07 & .74 & 8.14 & 8.98 & .73 & 1.23 & .224 \\
\hline \multirow[t]{2}{*}{ PATSOR Total } & 34.62 & 10.62 & .91 & 34.75 & 10.26 & .91 & -.67 & .505 \\
\hline & \multicolumn{3}{|c|}{ General Public } & \multicolumn{3}{|c|}{ Forensic Students } & & \\
\hline ACT Traditionalism & 32.68 & 9.31 & .91 & 23.98 & 10.36 & .9 & -4.29 & $<.001$ \\
\hline
\end{tabular}

Note: $\mathrm{PSO}=$ perceptions of sex offenders; PATSOR = public attitudes towards sex offender rehabilitation.

nor the total PATSOR scale. Finally, the general public scored significantly higher on traditionalism $(d=0.88)$ than students of forensic psychology, ${ }^{1}$ deeming it as a control variable in subsequent analyses.

\subsection{Multivariate analyses of covariance}

Two $2 \times 2$ MANCOVAs were used to examine the effects of knowledge (public vs forensic psychology students) and perpetrator sex (male vs female) on perceptions of individuals with sex offences (PSO) and their rehabilitation (PATSOR), whilst controlling for traditionalism. ${ }^{2}$ For the total scale scores, there was a main effect of population type on PSO and PATSOR $\left(F(4,93)=10.37, p<.001\right.$; Wilk's $\left.\Lambda=0.692, \eta^{2}=0.308\right)$ but no significant main effect $(F(4,93)=2.11, p=.085$; Wilk's $\Lambda=0.917$, $\left.\eta^{2}=0.083\right)$ or interaction $(F(4,93)=0.648, p=.630$; Wilk's $\Lambda=0.973$, $\eta^{2}=0.027$ ) for perpetrator sex. Subsequent test of between-subject effects analyses indicated there was a significant difference in public and forensic psychology students for the PSO and PATSOR total scores for both adult and child victims.

Similarly, for the subscales, there was a significant main effect of population type on PSO and PATSOR subscales $(F(10,87)=4.67$, $p<.001$; Wilk's $\Lambda=0.651, \eta^{2}=0.481$ ), but no significant main effect $\left(F(10,87)=1.58, p=.125\right.$; Wilk's $\left.\Lambda=0.846, \eta^{2}=0.349\right)$ or interaction $\left(F(10,87)=0.74, p=.681\right.$; Wilk's $\left.\Lambda=0.921, \eta^{2}=0.027\right)$ for perpetrator sex. Subsequent between-subject effects analyses indicated there was a significant difference in public and forensic psychology students for the PSO Sentencing and Management and Risk Perception subscales as well as PATSOR's Rehabilitation subscale, for both adult and child victims. Additionally, the group differed significantly on the PATSOR Offender Residence subscale, for adult victims only. Across all significant comparisons, the public had higher means than students of forensic psychology, indicating that they had more punitive and harsher views of sex offenders and their rehabilitation than the students (see Table 2 for statistics and mean scores).

\section{Discussion}

This paper contributes to our understanding of the perceptions of individuals with sexual offences and their rehabilitation. In line with our predictions, the main factors influencing these perceptions were the age of the victim and knowledge around sex offenders and their rehabilitation (operationalised through prior education in forensic psychology).

\footnotetext{
1 Expectedly, there was also a significant difference in age between students of forensic psychology and members of the general population $(t(99)=-10.32$, $p<.001, d=1.89$ ).

2 A MANOVA without traditionalism as a control was conducted showing the same significant effects as seen in the MANCOVA controlling for traditionalism. Therefore, while there was a significant difference in traditionalism scores between the population types, this did not solely account for the differences in PSO and PATSOR ratings for the two groups.
}

Specifically, more punitive views were endorsed for sex offenders with child (relative to adult) victims, and by the general public (relative to forensic psychology students), independent of their differences in selfreported traditionalism. Contrary to our predictions, there were no differences between perpetrator sex. These results are discussed in more detail in relation to the highlighted theoretical propositions and extant literature, as well as implications of our findings for policy and awareness raising around reintegration and rehabilitation of sex offenders.

\subsection{Offence characteristics: victim age and perpetrator sex}

Regarding victim age, perceptions differed for the overall perceptions of sex offenders, suggesting that individuals with sexual offences against child victims were viewed more negatively than those with offences against adult victims. In line with the theoretical framework of Just Deserts (Carlsmith et al., 2002), individuals with sexual offences against children may be seen more negatively, because their crimes are considered to be more abhorrent, relative to adult-victim offences (Rogers et al., 2011; Weekes et al., 1995) and they are more deserving of harsher punishments (Hilinski-Rosick, Freiburger, \& Verheek, 2014; Mancini \& Mears, 2010; Pickett et al., 2013). Though the effect of victim age on the perceptions of sex offenders was a general one rather than specifically driven by any of the facets, a marginal effect was observed for risk perception suggesting that greater perceived threat might underpin more negative perceptions for sex offenders with child victims. Previous research suggests that in particular parents perceive greater threat from individuals with sexual offences against children (Gurland \& Grolnick, 2003; Mancini, Shields, Mears, \& Beaver, 2010). However, the current sample comprised of $60 \%$ students (with younger age and potentially lower frequency of parenthood), which may explain the weaker effect. Thus, future research around the perceived threat of sex offenders with child victims should also aim to account for some of the variation as a function of parenthood.

Nevertheless, victim age did not differentially impact perceptions around rehabilitation or knowledge of offender residence. Thus, even though individuals with sexual offences against children were viewed more negatively (possibly driven by perceptions of risk), this did not transfer to more adverse beliefs around their rehabilitation as compared to individuals with sexual offences against adults. Additionally, stereotype endorsement did not differ between adult and child victims, which implies there exists little difference in the stereotypical views held about individuals with sexual convictions, regardless of the age of the victim. Previous literature also documents that stereotypical views and societal values are pro-victim in general, regardless of victim characteristics such as age (Davies and Rogers, 2009).

In terms of perpetrator sex, while research into females with sexual convictions is increasing in frequency (Ten Bensel, Gibbs, \& Burkey, 2019), this is the first research to examine perceptions for male and female perpetrator sex in sexual offence vignettes and as a function of victim age. This allowed us to test both the Chivalry (Anderson, 1976; 
Table 2

Univariate Between-Subject Effects for population and perpetrator sex.

\begin{tabular}{|c|c|c|c|c|c|c|c|c|}
\hline \multirow[t]{2}{*}{ Scales } & \multicolumn{4}{|c|}{ Population type } & \multicolumn{4}{|c|}{ Perpetrator sex } \\
\hline & F-Value & $p$ & Public & Student & F-Value & $p$ & Male & Female \\
\hline \multicolumn{9}{|l|}{ PSO scales: } \\
\hline Sentencing (Adult) & 33.83 & $<.001$ & 32.3 & 14.34 & .49 & .943 & 22.04 & 20.88 \\
\hline Sentencing (Child) & 32.65 & $<.001$ & 33.15 & 15.48 & 1.81 & .182 & 21.9 & 23.04 \\
\hline Stereotype (Adult) & .87 & .354 & 11.33 & 9.48 & .49 & .484 & 9.9 & 10.51 \\
\hline Stereotype (Child) & 1.52 & .22 & 11.63 & 9.44 & .41 & .523 & 10.04 & 10.57 \\
\hline Risk Perception (Adult) & 6.45 & .013 & 19.95 & 17.43 & 1.31 & .256 & 19.02 & 17.84 \\
\hline Risk Perception (Child) & 11.81 & .001 & 20.93 & 17.87 & .419 & .519 & 19.00 & 19.16 \\
\hline Total (Adult) & 28.98 & $<.001$ & 63.58 & 41.25 & .000 & .990 & 50.96 & 49.24 \\
\hline Total (Child) & 31.75 & $<.001$ & 65.7 & 42.79 & 2.03 & .157 & 50.94 & 52.76 \\
\hline \multicolumn{9}{|l|}{ PATSOR scales: } \\
\hline Rehabilitation (Adult) & 31.4 & $<.001$ & 33.1 & 21.75 & .115 & .735 & 26.44 & 26.06 \\
\hline Rehabilitation (Child) & 16.87 & $<.001$ & 32.65 & 23.05 & .006 & .937 & 27.14 & 26.57 \\
\hline Offender Residence (Adult) & 7.6 & .007 & 9.48 & 7.66 & .007 & .935 & 8.52 & 8.24 \\
\hline Offender Residence (Child) & 2.06 & .154 & 8.98 & 7.59 & .49 & .483 & 8.1 & 8.18 \\
\hline Total (Adult) & 33.24 & $<.001$ & 42.57 & 29.41 & .082 & .775 & 34.96 & 34.29 \\
\hline Total (Child) & 16.61 & $<.001$ & 41.58 & 30.64 & .066 & .798 & 35.24 & 34.75 \\
\hline
\end{tabular}

Note: PSO = perceptions of sex offenders; PATSOR = public attitudes towards sex offender rehabilitation.

Fernando Rodriguez et al., 2006) and double-deviance (Heidensohn, 1989) hypotheses. However, we found no differences in perceptions as a function of perpetrator sex whether for adult or child victims. This conflicts the literature that suggests males with sexual offences are typically perceived more negatively (Gakhal \& Brown, 2011; Godfrey et al., 2005) and females more leniently (c.f., Chivalry hypothesis). The double-deviance theory on the other hand proposes that females who commit counter-stereotypical offences (such as sexual offending) might be perceived harsher for those crimes (Viki et al., 2005). Thus, when offences deviate from gender stereotypes (e.g., being more caring, motherly), crimes are considered to be more impactful and female offenders might be perceived equally bad as male offenders. Our findings appear in line with this supporting the double-deviance hypothesis. However, at the same time we would have expected to see even harsher views towards female sex offenders when the victim was a child, but even this extreme of counter-stereotypical behaviour did not fully flip the gender discrepancy. Finally, increasing media coverage concerning sex offences with female perpetrators may have led to a more general shift towards equal perceptions of sexual offences committed by females and males, suggesting gender conflated perceptions in general, an interesting avenue of future investigation (Lewis \& Stanley, 2000).

\subsection{Perceiver characteristics: role of traditionalism and education in forensic psychology}

As predicted, there was a main effect of knowledge or awareness operationalised through education in forensic psychology - on perceptions of individuals with sexual convictions and their rehabilitation. Specifically, across all measures (apart from stereotype endorsement), the general population reported harsher and more punitive attitudes than forensic psychology students. Such findings largely support previous literature suggesting that training in forensic psychology and raising awareness/knowledge about individuals with sexual convictions and their rehabilitation reduces negative viewpoints (Kleban et al., 2012). The absence of an effect of education on the stereotype endorsement subscale suggests that biased beliefs about individuals with sexual offences are nevertheless prevalent across both experimental groups. This means that whilst education pertaining to sexual offences can impact perceptions of risk and rehabilitation, it may not be enough to break the more generally pervasive stereotypical views around sex offenders. This may still point towards the impact of Moral Panic (Cohen, 1972), with stereotypes towards individuals with sexual offences reinforced by everyday media, and thus, held across the population, independent of education and its beneficial impact on perceptions (or knowledge) of actual risk and possible rehabilitation. Ultimately, this suggests that in order to reduce the stigmatisation of individuals with sexual offences and allow for successful reintegration, education must be implemented.

Importantly, although baseline comparisons indicated that students of forensic psychology had fewer traditional views relative to the general population (mirroring work by Bryant, 2003 and Kumar, 2016), traditionalism neither accounted for the differences in the perceptions of individuals with sexual convictions nor their rehabilitation. Thus, although traditionalism may be linked to harsher views on sentencing (Huang, Finn, Ruback, \& Friedmann, 1996); it did not explain the current findings. Replication of our findings across larger cohorts is essential to validate these claims, and to delineate the distinct role of traditionalism in the perception of sexual offences.

\subsection{Implications}

Our findings have potential impact for the successful rehabilitation and reintegration of individuals with sexual convictions back into society. Previous literature clearly indicates that negative societal views of this group of offenders can result in both increased anxiety, hopelessness, and depression for the offenders (Tewksbury \& Lees, 2006), as well as reduced success in their rehabilitation (Schiavone \& Jeglic, 2009). Findings reported here propose a benefit for the use of education in forensic psychology to shift the general public's perceptions around risk, needs and rehabilitation of individuals with sexual offences; potentially attenuating the misconceptions of risk and recidivism delineated in Alper and Durose (2019). Future research should seek to develop and test the effectiveness of such interventions and outline the degree to which awareness raising around their benefits might combat the often sensationalized media reports related to this offender group. As such, this education might form part of the development of policy associated with the generation and functioning of sex offender rehabilitation programmes; bringing said education around these issues into the public sector. Moreover, and in line with implications discussed within Socia, Rydberg, and Dum (2019), the provision of education has added importance for those individuals tasked with contributing to the decision to release and/or sanction post-release policy conditions on individuals with sexual convictions. The provision of education pertaining to such individuals (including the benefit and adherence to rehabilitation programmes) appears essential as a means of alleviating pre-cognitions about the danger they pose to the general public (Cromer \& Goldsmith, 2010; Rogers \& Ferguson, 2011).

\subsection{Limitations and future research}

Although considered a well-established and efficacious methodology for identifying perceptions (Schoenberg \& Ravdal, 2000), details of sexual offences were presented via vignettes, which may not fully 
resemble the nuanced details of real-life offences. Indeed, the current vignettes were kept purposefully brief containing only the pertinent information. In reality, we are typically confronted with more detail around offences, which might further reinforce biased perceptions and affect decision making (e.g., judicial decisions around sentencing or offender management). Second, there was a significant age difference between the general public and the forensic psychology students in the current samples. This is important because traditionalism tends to be greater in older populations (Eaves et al., 1997); potentially biasing our interpretation of the data. However, since traditionalism did not affect the current results, this may be less of an issue. Nevertheless, future replications should consider matched, paired-sample approaches to mitigate these limitations. Finally, the sample size of the study is relatively small and demographically restricted. Future replication would benefit in studying a larger and more diverse sample to increase generalisability.

\subsection{Conclusions}

This study is the first to simultaneously consider the roles of perpetrator sex, victim age, offence-relevant education in forensic psychology and traditionalism on perceptions of individuals with sexual convictions and their rehabilitation. The results indicate that perceptions of individuals with sexual convictions are viewed much more punitively by the general population than by students of forensic psychology, independent of their greater traditionalism. Results were discussed in the context of several pertinent psychological theories around factors influencing perceptions of sex offenders, whilst acknowledging study limitations and future directions to test these further. Finally, the findings highlight the need for the integration of public education around individuals with sexual offences in established sex offender treatment programmes in order to shift these perceptions.

\section{CRediT author statement}

Megan Rothwell: Conceptualization, Methodology, Investigation, Formal Analysis, Writing - Original Draft. Dean Fido: Writing- Review \& Editing. Nadja Heym: Conceptualization, Methodology, WritingReviewing and Editing, Supervision.

\section{Declaration of competing interest}

The authors declare that they have no known competing financial interests or personal relationships that could have appeared to influence the work reported in this paper.

\section{References}

Alper, M., \& Durose, M. R. (2019). Recidivism of sex ofenders released from state prison: A 9year follow-up (2005-14) (p. NCJ251773). Bureau of Justice Statistics.

Anderson, E. A. (1976). The chivalrous treatment of the female offender in the arms of the criminal justice system. Social Problems, 23, 349-357.

Bizumic, B., \& Duckitt, J. (2018). Investigating right wing authoritarianism with a very short authoritarianism scale. Journal of Social and Political Psychology, 6(1), 129-150.

Bjerkli, B. (1996). Land use, traditionalism, and rights. Acta Borealia, 13(1), 3-21.

Brown, S., Deakin, J., \& Spencer, J. (2008). What people think about the management of sex offenders in the community. The Howard Journal of Criminal Justice, 47(3), 259-274.

Bryant, A. N. (2003). Changes in attitudes toward women's roles: Predicting gender-role traditionalism among college students. Sex Roles, 48(3-4), 131-142.

Bumby, K. M., \& Hansen, D. J. (1997). Intimacy deficits, fear of intimacy, and loneliness among sexual offenders. Criminal Justice and Behavior, 24(3), 315-331.

Carlsmith, K. M., Darley, J. M., \& Robinson, P. H. (2002). Why do we punish? Deterrence and just deserts as motives for punishment. Journal of Personality and Social Psychology, 83, 284-299.

Cohen, S. (1972). Folk devils and moral panics. New York, NY: MacGibbon and Kee.

Cortoni, F., Hanson, R. K., \& Coache, M.È. (2010). The recidivism rates of female sexual offenders are low: A meta-analysis. Sexual Abuse, 22(4), 387-401.

Craig, L. A. (2005). The impact of training on attitudes towards sex offenders. Journal of Sexual Aggression, 11(2), 197-207.
Cromer, L. D., \& Goldsmith, R. E. (2010). Child sexual abuse myths: Attitudes, beliefs, and individual differences. Journal of Child Sexual Abuse, 19(6), 618-647.

Davies, M., \& Rogers, P. (2009). Perceptions of blame and credibility towards victims of childhood sexual abuse: Differences across victim age, victim-perpetrator relationship, and respondent gender in a depicted case. Journal of Child Sexual Abuse, 18(1), 78-92.

Dozier, A. (2009). Factors influencing the attitudes of college students towards rehabilitation or punishment of criminal offenders. M.A. Thesis. Department of Political Science, Texas State University.

Duckitt, J., Bizumic, B., Krauss, S. W., \& Heled, E. (2010). A tripartite approach to rightwing authoritarianism: The authoritarianism-conservatism-traditionalism model. Political Psychology, 31(5), 685-715.

Eaves, L., Martin, N., Heath, A., Schieken, R., Meyer, J., Silberg, J., et al. (1997). Age changes in the causes of individual differences in conservatism. Behavior Genetics, 27(2), 121-124.

Elliott, I. A., \& Ashfield, S. (2011). The use of online technology in the modus operandi of female sex offenders. Journal of Sexual Aggression, 17(1), 92-104.

Fernando Rodriguez, S., Curry, T. R., \& Lee, G. (2006). Gender differences in criminal sentencing: Do effects vary across violent, property, and drug offenses? Social Science Quarterly, 87(2), 318-339.

Gakhal, B. K., \& Brown, S. J. (2011). A comparison of the general public's, forensic professionals', and students' attitudes towards female sex offenders. Journal of Sexual Aggression, 17(1), 105-116.

Galeste, M. A., Fradella, H. F., \& Vogel, B. (2012). Sex offender myths in print media: Separating fact from fiction in US newspapers. Western Criminology Review, 13, 4.

Gidycz, C. A., Orchowski, L. M., King, C. R., \& Rich, C. L. (2008). Sexual victimization and health-risk behaviours. Journal of Interpersonal Violence, 23(6), 744-763.

Godfrey, B. S., Farrall, S., \& Karstedt, S. (2005). Explaining gendered sentencing patterns for violent men and women in the late-Victorian and Edwardian period. British Journal of Criminology, 45(5), 696-720.

Griffin, T., \& Wooldredge, J. (2006). Sex-based disparities in felony dispositions before versus after sentencing reform in Ohio. Criminology, 44(4), 893-923.

Gurland, S. T., \& Grolnick, W. S. (2003). Children's expectancies and perceptions of adults: Effects on rapport. Child Development, 74(4), 1212-1224.

Harper, C. A., \& Hogue, T. E. (2014). Measuring public perceptions of sex offenders: Reimagining the community attitudes toward sex offenders scale. Psychology, Crime and Law, 21(5), 452-470.

Heidensohn, F. (1989). Gender and crime (pp. 85-111). Crime and society.

Hilinski-Rosick, C. M., Frieburger, T. L., \& Verheek, A. (2014). The effects of legal and extralegal variables on the sentences of sex offenders. Victims and Offenders, 9(3), $334-351$.

Huang, W. W., Finn, M. A., Ruback, R. B., \& Friedmann, R. R. (1996). Individual and contextual influences on sentence lengths: Examining political conservatism. The Prison Journal, 76(4), 398-419.

Hugo, C. J., Boshoff, D. E., Traut, A., Zungu-Dirwayi, N., \& Stein, D. J. (2003). Community attitudes toward and knowledge of mental illness in South Africa. Social Psychiatry and Psychiatric Epidemiology, 38(12), 715-719.

Jost, J. T., Glaser, J., Kruglanski, A. W., \& Sulloway, F. J. (2003). Political conservatism as motivated social cognition. Psychological Bulletin, 129(3), 339.

Kernsmith, P. D., Craun, S. W., \& Foster, J. (2009). Public attitudes toward sexual offenders and sex offender registration. Journal of Child Sexual Abuse, 18(3), 290-301.

King, L. L., \& Roberts, J. J. (2017). The complexity of public attitudes toward sex crimes. Victims and Offenders, 12(1), 71-89.

Kirchengast, T. (2010). Proportionality in sentencing and the restorative justice paradigm: 'Just deserts' for victims and defendants alike? Criminal law and philosophy, $4(2), 197-213$.

Kleban, H., \& Jeglic, E. (2012). Dispelling the myths: Can psychoeducation change public attitudes towards sex offenders? Journal of Sexual Aggression, 18(2), 179-193.

Kumar, S. (2016). Career choice and college students: Parental influence on career choice traditionalism among college students in selected cities in Ethiopia. International Journal of Psychology and Educational Studies, 3(3), 23-30.

Laczko-Kerr, I., \& Berliner, D. C. (2003). Harm's way: How under certified teachers hurt their students. Educational Leadership, 60(8), 34-39.

Levenson, J. S., Brannon, Y. N., Fortney, T., \& Baker, J. (2007). Public perceptions about sex offenders and community protection policies. Analyses of Social Issues and Public Policy, 7(1), 137-161.

Lewis, C. F., \& Stanley, C. R. (2000). Women accused of sexual offenses. Behavioural Sciences \& the Law, 18(1), 73-81.

Lösel, F., \& Schmucker, M. (2005). The effectiveness of treatment for sexual offenders: A comprehensive meta-analysis. Journal of Experimental Criminology, 1(1), 117-146.

Mancini, C., \& Mears, D. P. (2010). To execute or not to execute? Examining public support for capital punishment of sex offenders. Journal of Criminal Justice, 38(5), 959-968.

Mancini, C., Shields, R. T., Mears, D. P., \& Beaver, K. M. (2010). Sex offender residence restriction laws: Parental perceptions and public policy. Journal of Criminal Justice, 38(5), 1022-1030.

McKimmie, B. M., \& Masser, B. (2010). The effect of gender in the courtroom. In J. Adler (Ed.), Forensic psychology: Concepts, debates and practice (2nd ed., pp. 127-154).

Mears, D. P., Mancini, C., Gertz, M., \& Bratton, J. (2008). Sex crimes, children, and pornography: Public views and public policy. Crime \& Delinquency, 54(4), 532-559.

Nunnally, J. C. (1978). Psychometric theory (2nd ed.). New York: McGraw-Hill.

Olver, M. E., \& Barlow, A. A. (2010). Public attitudes toward sex offenders and their relationship to personality traits and demographic characteristics. Behavioural Sciences \& the Law, 28(6), 832-849. 
Pickett, J. T., Mancini, C., \& Mears, D. P. (2013). Vulnerable victims, monstrous offenders, and unmanageable risk: Explaining public opinion on the social control of sex crime. Criminology, 51(3), 215-232.

Radley, L. (2001). Attitudes towards sex offenders. Forensic Update, 66, 5-9.

Redlich, A. (2001). Community notification: Perceptions of its effectiveness in preventing child sexual abuse. Journal of Child Sexual Abuse, 10(3), 91-116.

Rogers, P., \& Davies, M. (2007a). Perceptions of victims and perpetrators in a depicted child sexual abuse case: Gender and age factors. Journal of Interpersonal Violence, 22(5), 566-584.

Rogers, P., \& Davies, M. (2007b). Perceptions of credibility and attributions of blame towards victim in a childhood sexual abuse case: Gender and age factors. Journal of Interpersonal Violence, 22, 566-584.

Rogers, D. L., \& Ferguson, C. J. (2011). Punishment and rehabilitation attitudes toward sex offenders versus nonsexual offenders. Journal of Aggression, Maltreatment \& Trauma, 20(4), 395-414.

Rogers, P., Hirst, L., \& Davies, M. (2011). An investigation into the effect of respondent gender, victim age, and perpetrator treatment on public attitudes towards sex offenders, sex offender treatment, and sex offender rehabilitation. Journal of Offender Rehabilitation, 50(8), 511-530.

Rosselli, M. K., \& Jeglic, E. L. (2017). Factors impacting upon attitudes toward sex offenders: The role of conservatism and knowledge. Psychiatry, Psychology and Law, 24(4), 496-515.

Schoenberg, N. E., \& Ravdal, H. (2000). Using vignettes in awareness and attitudinal research. International Journal of Social Research Methodology, 3(1), 63-74.

Singer, L., \& Cooper, S. (2009). Improving public confidence in the criminal justice system: An evaluation of a communication activity. The Howard Journal of Criminal Justice, 48(5), 485-500.
Socia, K. M., Rydberg, J., \& Dum, C. P. (2019). Punitive attitudes towards individuals convicted of sex offence: A vignette study. Justice Quarterly.

Steffensmeier, D., Zhong, H., Ackerman, J., Schwartz, J., \& Agha, S. (2006). Gender gap trends for violent crimes, 1980 to 2003: A UCR-NCVS comparison. Feminist Criminology, 1(1), 72-98.

Ten Bensel, T., Gibbs, B., \& Burkey, C. R. (2019). Female sex offenders: Is there a difference between solo and co-offenders? Journal of Interpersonal Violence, 34(19), 4061-4084.

Tewksbury, R., \& Lees, M. (2006). Perceptions of sex offender registration: Collateral consequences and community experiences. Sociological Spectrum, 26(3), 309-334.

Valiant, P. M., Furac, C. J., \& Antonowicz, D. H. (1994). Attitudes towards sex offenders by female undergraduate university students enrolled in a psychology program. Social Behavior and Personality, 22(2), 105-110.

Viki, G. T., Massey, K., \& Masser, B. (2005). When chivalry backfires: Benevolent sexism and attitudes towards Myra Hindley. Legal and Criminological Psychology, 10, $109-120$.

Wakefield, H. (2006). The vilification of sex offenders: Do laws targeting sex offenders increase recidivism and sexual violence. Journal of Sexual Offender Civil Commitment: Science and the Law, 1(1), 141-149.

Weekes, J. R., Pelletier, G., \& Beaudette, D. (1995). Correctional officers: How do they perceive sex offenders? International Journal of Offender Therapy and Comparative Criminology, 39(1), 55-61.

Weiss, K. G. (2010). Too ashamed to report: Deconstructing the shame of sexual victimization. Feminist Criminology, 5(3), 286-310.

Willis, G. M., Levenson, J. S., \& Ward, T. (2010). Desistance and attitudes towards sex offenders: Facilitation or hindrance? Journal of Family Violence, 25(6), 545-556. 